\title{
Social Media in Agriculture - A Profile Analysis
}

\author{
G. P. Sandeep ${ }^{1 *}$, P. Prashanth ${ }^{1}$, M. Sreenivasulu ${ }^{1}$ and A. Madhavilata ${ }^{2}$ \\ ${ }^{1}$ Department of Agricultural Extension, ${ }^{2}$ Department of Agronomy-College of Agriculture, \\ Rajendranagar, PJTSAU, India \\ *Corresponding author
}

\section{A B S T R A C T}

\begin{tabular}{|l|}
\hline Key w o r d s \\
Social Media, \\
Agriculture, \\
Developments in \\
ICTs
\end{tabular}

Social media tools are playing a major role in the dissemination of farm information. Social media has revolutionized the way of communication in the $21^{\text {st }}$ century. The usage of social media increasing day by day in rural areas and its usage touched almost every field. With changes in communication technologies, the extension system also adopted new developments in ICTs to reach farmers more effectively. There are many initiatives taken by institutions related to agriculture to reach farmers round the clock with the help of social media. This paper focused to study the profile analysis of farmers using social media. The Ex-post facto research design was adopted for the study with a sample of 120 respondents, covering all three districts form the Southern Telangana Zone of Telangana state. From the analysis, it was found that majority of the respondents belonged to middle age $(47.50 \%)$ with the low level of digital literacy $(45.00 \%)$ having a low level of farming experience $(44.17 \%)$ and small size landholding $(50.83 \%)$, poor social media network $(50.00 \%)$, medium social media usage $(60.00 \%)$, low information processing $(65.00 \%)$, low mode of access and preference $(61.67 \%)$, medium readiness to accept information $(62.50 \%)$ and a medium level of social media participation $(54.17 \%)$.

\section{Introduction}

Social media has originated since human beings started to communicate with each other. With a change in demand for faster transmission of messages, men have come out with numerous innovations with new forms of associations to facilitate information exchange among the people. Social media is one such innovation that is widely being used by people around the globe to connect with their peers and share information across a wide range of platforms in different forms such as text, video, photos and audios facilitated by different social media applications.

Social media is described as the latest communication technology through which mass method of communication along with a combination of two-way communication and which content is developed from two ends. They are an interactive network in which ICTs bequeath to modern society through the instrumentally of the internet and the telecommunication gadgets (Eke et al., 2014). 
Social media has been the fastest adopted media technology in the world as it took around 38 years for radio, 13 years for television, 4 years for iPod, 3 years for internet but one year for Facebook and 9 months for twitter to reach 50 million users (Chui et al., 2012). Social media is now everywhere used by all age groups of people in every walk of life as it has revolutionized the means of communication. It has engrossed the attention of millions of internet users as it is the fastest and cheapest means of communication brought about by advancement in the IT sector.

There were 3.81 billion users of social media tools around the globe during 2020 and Youtube, Facebook, and Whatsapp leading social media networks in India (www.statista.com, 2020). India's internet users grew by 40 per cent, while globally the growth was 9 per cent, making the growth 4 times higher in India (ET tech, 2016). Social media penetration is 14 per cent while the growth of social media users in 2016-2017, has been 40 per cent ( 55 million), which is the second-highest world (We are social, 2017). It is evident from the recent trends that social media is gaining increasing popularity among farmers, as it is incorporated into their daily routines.

The social media is becoming a very important tool in farming to connect people to people because of its ability to connect with farmers and experts around the world over large geographical distances, Social media play a very important role in enhancing interactions and information flows among different people involved in agricultural innovation and enhance capacities of agricultural extension and advisory service providers. The power of social media is in the features that allow it to be applied to a whole range of applications that involve interaction between people (Chui et al., 2012).Social media has been impacting various sectors including the agriculture sector.

In Telangana, the information in social media is disseminating by agriculture research institutes, state agricultural university, mass media channels, state government departments, and NGOs majorly and individuals attempt also made by people in the interest of proving agriculture information to farmers round the clock. Thousands of videos relating to agriculture are available on youtube in Telugu language and Whatsapp groups are familiar at field level among farmers to share and discuss with other farmers and experts.

\section{Materials and Methods}

The state of Telangana and southern Telangana zone (STZ) region was purposively selected for the study. All three erstwhile districts i.e. Rangareddy, Mahaboobnagar, and Nalgonda under STZ was selected for the study. Two mandals form each district were selected randomly and two villages from each mandal were selected randomly. A sample size of 10 farmers from each village selected purposively, thus in a total of 120 farmers.

The data from the respondents was collected with the help of interview schedule. The data collected was analysed and interpretations were drawn based on results. The statistical techniques frequency, percentage, mean, and inclusive class interval method were followed for analyse data, and accordingly, respondents were classified into different groups.

\section{Results and Discussion}

The data was collected from the respondents on the selected profile characteristics were analysed, interpreted, and accordingly the following results and conclusion were drawn. 
Age

Age was operationalized as the chronological age of the respondent in terms of the total number of years completed at the time of conducting the study. Data presented in table.1 shows that the majority $(47.50 \%)$ of the farmers using social media belong to middle age category followed by young $(36.67 \%)$ and old age $(15.83 \%)$ categories. From the table. 1 it can be depicted that the majority of farmers using social media belong to middle and young age. This may be due to the middle and young are using social media than old. The above findings are in consonance with the results of Meera et al., (2018).

\section{Digital literacy}

Digital literacy was operationalized as the extent to which farmers are skilled to operate ICT tools to get basic information from social media. Data presented in table 2. shows that the majority $(45.00 \%)$ of the farmers using social media was having a low level of digital literacy followed by a medium level of digital literacy $(40.00 \%)$ and a high level of digital literacy $(15.00 \%)$. It can be depicted that the majority of the farmers using social media belong to the low and medium level of digital literacy.

The findings are in line with the findings of Laxmipriya (2017). This may be due to the reason that many users are not aware of how to create social media accounts, password management. The majority of the farmers are using social media accounts created by others for them on their mobile.

\section{Farming experience}

It was operationalized as the number of years of experience a respondent had in farming and allied sectors. Data presented in table 3 . shows that the majority $(41.17 \%)$ of the respondent's farmers using social media having a low farming experience followed by medium farming experience $(42.50 \%)$ and high farming experience (13.33\%).

From table3. it can be depicted that the majority of farmers using social media have a medium and low level of farming experience. Results are in agreement with Meera et al., (2018).This may be due to the majority of the farmers using social media belong to young and middle age.

\section{Farm size}

This was operationalized as the number acres owned by the respondents at the time of conducting the study. Data presented in table 4. shows that the majority $(50.83 \%)$ of farmers using social media having small size landholding followed by having smallmedium size $(28.33 \%)$, marginal holding $(10.83 \%)$, medium holdings $(07.50 \%)$ and large size holdings (02.50). It can be depicted that farmers using social media have small and small-medium. Plausible reason could be the ancestral transfer of land holding from generation to generation. The results get support from the findings of Anil (2018).

\section{Social media network}

This was operationalised as respondent interaction with the various extension personnel, NGOs, family members, relatives and other personnel for agricultural and allied sectors related information with help of social media platforms. The respondents were classified into low, medium and high categories based on inclusive class interval. Data presented in table5. shows that the majority $(50.00 \%)$ of farmers using social media have poor social media network followed by average $(41.63 \%)$ of social media network and good $(08.33 \%)$. 
Data presented in Table 6. shows that farmers using social media have more frequency of contact with family members with the mean (4.67) followed by neighbors (4.22), local leaders (3.92), progressive farmer (3.82), agricultural extension officer (3.73), agriculture officer (3.42), university scientist (3.23), financial institute (3.17), input agency (2.93) and NGO (2.31).

\section{Social media usage}

It was operationalised as frequency of using social media platforms by respondents. The respondents were grouped into three categories based on inclusive class interval technique. Data presented in Table 4.8. shows that the majority $(60.00 \%)$ of social media users have a medium level of social media usage followed by a low level $(23.33 \%)$ and high $(16.73 \%)$.

Data presented in Table 8. shows that messaging platforms ranked top with the mean (4.78) in most used social media platform by farmers using social media followed by media sharing platforms (3.94), social networking sites (3.53), microblogs (1.30) and blogs (1.21) ranked least.It was found that messaging platforms and media sharing are using more frequently by respondents. Blogs were the least using platforms among all by respondents.

\section{Information processing}

Information processing operationalised as activities performed by respondents for synthesis, evaluation and storage of agriculture information received from social media. Hence information processing is defined as a composite of preservation of information and method of information evaluation. Data presented in Table 9. shows that the majority $(65.00 \%)$ of social media users have a low level of information processing in farmers using social media followed by medium level $(31.67 \%)$ and high level $(3.33 \%)$. From the table 9 , it can be depicted that farmers using social media have a low level of information processing. The results are in agreement with Aparna et al., (2014). This may be due to the reason that majority of the farmers using social media just cursory look in preserving the agriculture information available in social media and they are less frequently asking experts during evaluating the information received to them on social media.

Data presented in table10. shows that cursory look ranked top with mean (4.76) in information processing among farmers using social media followed by note in dairy (store in mobile) (3.82), memorize it (3.51), preserve literature and use when needed (1.60) and maintain subject matter file (1.33). It can also observed, that discussion with family ranked top with mean (4.13) in the method of evaluation among farmers using social media followed by a discussion with friends (4.06), discussion with progressive farmers (3.92), discussion with relatives (3.76) and discussion with agriculture expert of SAU/ state department / Input dealers (3.52).

From the table 10, it can be depicted that farmers using social media adopted the cursory look, storing in mobile and memorizing methods in the preservation of information received or available on social media and evaluating information by discussing it with family members, friends and progressive farmers.

\section{Mode of access and preference}

Mode of access was operationalised availability of different social media platforms to respondents to access agriculture and other information. Preference was 
operationalised choice or interest or purpose or need of using social media platforms as perceived by the respondents.Data presented in Table 11. shows that the majority (61.67\%) of the respondents have a poor level mode of access and preference towards social media platforms followed average level $(35.50 \%)$ and good level $(5.83 \%)$.

Table.1 Distribution respondents according toage $(\mathrm{n}=120)$

\begin{tabular}{|c|c|c|c|}
\hline S.No & Age & Frequency & Percentage \\
\hline $\mathbf{1 .}$ & Young age (23-36 years) & 44 & 36.67 \\
\hline $\mathbf{2 .}$ & Middle age (37-49 years) & 57 & 47.50 \\
\hline $\mathbf{3 .}$ & Old age (50 - 62years) & 19 & 15.83 \\
\hline & Total & 120 & 100.00 \\
\hline
\end{tabular}

Table.2 Distribution of respondents based on digital literacy $(\mathrm{n}=120)$

\begin{tabular}{|c|c|c|c|}
\hline S.No & Digital literacy level & Frequency & Percentage \\
\hline $\mathbf{1 .}$ & Low level of digital literacy $(42-56)$ & 54 & 45.00 \\
\hline $\mathbf{2 .}$ & Medium level of digital literacy $(57-71)$ & 48 & 40.00 \\
\hline $\mathbf{3 .}$ & High level of digital literacy $(72-86)$ & 18 & 15.00 \\
\hline & Total & 120 & 100.00 \\
\hline
\end{tabular}

Table.3 Distribution of respondents based on their farming experience $(n=120)$

\begin{tabular}{|c|c|c|c|}
\hline S. No & Farming Experience & Frequency & Percentage \\
\hline $\mathbf{1 .}$ & Low $(3-13)$ & 53 & 44.17 \\
\hline $\mathbf{2 .}$ & Medium $(14-24)$ & 51 & 42.50 \\
\hline $\mathbf{3 .}$ & High $(25-35)$ & 16 & 13.33 \\
\hline & Total & 120 & 100.00 \\
\hline
\end{tabular}

Table.4 Distribution of respondents based on their farm size $(n=120)$

\begin{tabular}{|c|l|c|c|}
\hline S. No & \multicolumn{1}{|c|}{ Farm size } & Frequency & Percentage \\
\hline $\mathbf{1 .}$ & Marginal (Less than 1 ha) & 13 & 10.83 \\
\hline $\mathbf{2}$ & Small (Between 1 to 2 ha) & 61 & 50.83 \\
\hline $\mathbf{3 .}$ & Small-medium (Between 2 to 4 ha) & 34 & 28.33 \\
\hline $\mathbf{4 .}$ & Medium (Between 4 to 10 ha) & 09 & 07.50 \\
\hline $\mathbf{5 .}$ & Large (More than 10 ha) & 03 & 02.50 \\
\hline & Total & 120 & 100.00 \\
\hline
\end{tabular}

Table.5 Distribution of respondents based on social media network $(\mathrm{n}=120)$

\begin{tabular}{|l|c|c|c|}
\hline S. No. & Social media network & Frequency & Percentage \\
\hline $\mathbf{1 .}$ & Poor $(28-34)$ & 60 & 50.00 \\
\hline $\mathbf{2 .}$ & Average $(35-41)$ & 50 & 41.67 \\
\hline $\mathbf{3 .}$ & Good $(42-48)$ & 10 & 08.33 \\
\hline & Total & 120 & 100.00 \\
\hline
\end{tabular}


Table.6 Response analysis of social media network $(n=120)$

\begin{tabular}{|c|l|c|c|}
\hline S. No & Social media network & Mean score & Rank \\
\hline $\mathbf{1 .}$ & Agriculture Extension Officer & 3.73 & V \\
\hline $\mathbf{2 .}$ & Agriculture Officer & 3.42 & VI \\
\hline $\mathbf{3 .}$ & University Scientist & 3.23 & VII \\
\hline $\mathbf{4 .}$ & Input agency & 2.93 & IX \\
\hline $\mathbf{5 .}$ & Progressive farmer & 3.82 & IV \\
\hline $\mathbf{6 .}$ & NGO & 2.31 & X \\
\hline $\mathbf{7 .}$ & Financial Institute & 3.17 & VIII \\
\hline $\mathbf{8 .}$ & Neighbours & 4.22 & II \\
\hline $\mathbf{9 .}$ & Family members & 4.67 & I \\
\hline $\mathbf{1 0 .}$ & Local leaders & 3.92 & III \\
\hline
\end{tabular}

Table.7 Distribution of respondent based on their social media usage $(n=120)$

\begin{tabular}{|c|l|c|c|}
\hline S.No & \multicolumn{1}{|c|}{ Social media usage } & Frequency & Percentage \\
\hline 1. & Low $(10-13)$ & 28 & 23.33 \\
\hline 2. & Medium $(14-17)$ & 72 & 60.00 \\
\hline 3. & High $(18-21)$ & 20 & 16.67 \\
\hline & Total & 120 & 100.00 \\
\hline
\end{tabular}

Table.8 Response analysis of social media usage $(n=120)$

\begin{tabular}{|c|l|l|c|}
\hline S.No & Social media platforms & Mean & Rank \\
\hline $\mathbf{1 .}$ & Social networking sites & 3.55 & III \\
\hline 2. & Messaging platforms & 4.78 & I \\
\hline 3. & Media sharing platforms & 3.94 & II \\
\hline 4. & Microblogs & 1.30 & IV \\
\hline 5. & Blogs & 1.21 & V \\
\hline
\end{tabular}

Table.9 Distribution of respondent based on their information processing $(n=120)$

\begin{tabular}{|c|l|c|c|}
\hline S.No & Information processing & Frequency & Percentage \\
\hline $\mathbf{1 .}$ & Low $(28-33)$ & 78 & 65.00 \\
\hline $\mathbf{2 .}$ & Medium $(34-49)$ & 38 & 31.67 \\
\hline $\mathbf{3 .}$ & High $(40-44)$ & 04 & 03.33 \\
\hline & Total & 120 & 100.00 \\
\hline
\end{tabular}


Table.10 Response analysis of information processing $(n=120)$

\begin{tabular}{|c|c|c|c|}
\hline S.No & Particulars & Mean & Rank \\
\hline $\mathbf{A}$ & \multicolumn{3}{|l|}{ Preservation of information } \\
\hline 1. & Cursory look & 4.76 & I \\
\hline 2. & Note in dairy/ Field notes/ store in mobile & 3.82 & II \\
\hline 3. & Memorize it & 3.51 & III \\
\hline 4. & Preserve literature and use when needed & 1.60 & IV \\
\hline 5. & Maintain subject matter file & 1.33 & $\mathrm{~V}$ \\
\hline B. & \multicolumn{3}{|l|}{ Method of evaluation } \\
\hline 1. & Discussion with family & 4.13 & I \\
\hline 2. & Discussion with friends & 4.06 & II \\
\hline 3. & Discussion with relatives & 3.76 & IV \\
\hline 4. & Discussion with progressive farmer & 3.92 & III \\
\hline 5. & $\begin{array}{l}\text { Discussion with Agriculture expert of SAU/State } \\
\text { department/Input dealers }\end{array}$ & 3.52 & $\mathrm{~V}$ \\
\hline
\end{tabular}

Table.11 Distribution of respondent based on their mode of access and preference $(n=120)$

\begin{tabular}{|c|c|c|c|}
\hline S.No & Mode of access and preference & Frequency & Percentage \\
\hline 1. & Poor $(32-40)$ & 74 & 61.67 \\
\hline 2. & Average $(41-49)$ & 39 & 32.50 \\
\hline \multirow[t]{2}{*}{3.} & Good $(50-58)$ & 07 & 05.83 \\
\hline & Total & 120 & 100.00 \\
\hline
\end{tabular}

Table.12 Response analysis of the mode of access $(n=120)$

\begin{tabular}{|c|l|l|c|}
\hline S.No & Mode of access & Mean & Rank \\
\hline $\mathbf{1 .}$ & Youtube & 2.96 & II \\
\hline $\mathbf{2 .}$ & Whatsapp & 3.00 & I \\
\hline 3. & Facebook & 2.78 & III \\
\hline $\mathbf{4 .}$ & Twitter & 1.46 & IV \\
\hline $\mathbf{5 .}$ & Instagram & 1.30 & V \\
\hline 6. & Telegram & 1.16 & VI \\
\hline 7. & Pinterest & 1.03 & IX \\
\hline $\mathbf{8 .}$ & Flickr & 1.00 & X \\
\hline 9. & Micro blogs & 1.22 & VII \\
\hline $\mathbf{1 0 .}$ & Other blogs & 1.07 & VIII \\
\hline
\end{tabular}


Table.13 Response analysis of preference $(\mathrm{n}=120)$

\begin{tabular}{|c|l|c|c|}
\hline S.No & Preference & Mean & Rank \\
\hline $\mathbf{1 .}$ & News and events & 2.97 & IV \\
\hline $\mathbf{2 .}$ & Exchange of knowledge & 2.75 & VI \\
\hline $\mathbf{3 .}$ & Sharing information & 3.08 & II \\
\hline $\mathbf{4 .}$ & Connect with peers & 2.96 & V \\
\hline $\mathbf{5 .}$ & Share professional activities & 2.36 & VII \\
\hline $\mathbf{6 .}$ & Communicating & 2.99 & III \\
\hline $\mathbf{7 .}$ & Business activities & 1.73 & VIII \\
\hline $\mathbf{8 .}$ & Chatting & 3.58 & I \\
\hline
\end{tabular}

Table.14 Distribution of respondents based on their readiness to accept information $(\mathrm{n}=120)$

\begin{tabular}{|c|c|c|c|}
\hline S.No & Readiness to accept information & Frequency & Percentage \\
\hline $\mathbf{1 .}$ & Low $(10-12)$ & 25 & 20.83 \\
\hline $\mathbf{2 .}$ & Medium $(13-15)$ & 75 & 62.50 \\
\hline $\mathbf{3 .}$ & High $(16-18)$ & 20 & 16.67 \\
\hline & Total & 120 & 100.00 \\
\hline
\end{tabular}

Table.15 Distribution of respondents based on their social media participation $(n=120)$

\begin{tabular}{|c|c|c|c|}
\hline S.No & Social media participation & Frequency & Percentage \\
\hline $\mathbf{1 .}$ & Low $(7-9)$ & 46 & 38.33 \\
\hline $\mathbf{2 .}$ & Medium $(10-12)$ & 65 & 54.17 \\
\hline $\mathbf{3 .}$ & High $(13-15)$ & 09 & 07.50 \\
\hline & Total & 120 & 100.00 \\
\hline
\end{tabular}

\section{Mode of access}

It can be observed from the table 4.12., that whatsapp ranked topmost accessed social media platform among farmers using social media with mean (3.00) followed by youtube (2.96), facebook (2.78), twitter (1.46), instagram (1.46), telegram (1.16), micro blogs (1.22), other blogs (1.07), pinterest (1.03) and flickr (1.00). It can be depicted that farmers using social media had more access to social media platforms like whatsapp, youtube and facebook. The results are in agreement with Akankandelwa and Gabriel (2018).

\section{Preference}

It can be observed from the table13. that chatting ranked topmost preferred activity among farmers using social media platforms with mean (3.58) followed by sharing information (3.08), communicating (2.99), news and events (2.97), connecting with peers (2.96), exchange of knowledge (2.75), share professional activities (2.36) and business activities (1.73). It was found that chatting and information sharing are the preferred in using social media and using social media for business activity found least. 


\section{Readiness to accept information}

Readiness to accept information was operationalised as the degree to which respondents ready, willing, and prepared and consent to receive agriculture information available on social media. Data presented in table 14 . that the majority $(62.50 \%)$ of the respondents have a medium level of readiness to accept information among farmers using social media followed by low level $(20.83 \%)$ and high level (16.67\%). From the table 14, it can be depicted that farmers using social media have a medium level of readiness to accept information from social media.

\section{Social media participation}

It was operationalised as the degree of engagement and involvement of the respondents in social media platforms in connection with agriculture information.Data presented in table15. that majority $(54.20 \%)$ of the respondents have a medium level of social media participation among farmers using social media followed by low level $(38.30 \%)$ and high level (7.50\%).

In conclusion it was found that majority of the farmers using social media are belong to middle and young age with small size land holdings with the behaviour of medium level social media usage, medium level of readiness to accept information and medium social media participation which indicates that middle and young age farmers having positive sight towards the usage of social media. It also found that low digital literacy, the poor social media network, poor information processing, and poor mode of access and preference. It also observed form the results that majority of the farmers having only cursory look over available and receiving information form social media platforms and evaluating the information by discussing with family members and friends. This indicates that the extension system can work in areas of improving digital literacy among farmers, building strong location-specific social media networks, and bringing awareness availability of digital information through various ICT tools. It also found that Whatsapp, Facebook, and youtube are more familiar at field level among all social media platforms, extension personal should develop content accordingly in such a way that reach farmers more effectively through these social media platforms.

\section{References}

Akakandelwa, A and Gabriel, W. 2018. Students' social media use and its perceived impact on their social life: A case study of the university of zambia. International Journal of Multidisciplinary Research. 5 (3): 1-14.

Anil, K. 2018. Role of social media in dissemination of agricultural innovations in Haryana. M.Sc. $(\mathrm{Ag})$ Thesis. ChaudaryCharan Singh Haryana Agricultural University, Hisar, India.

Aparna, R., Meti, S.K and Goudappa, S.B. 2014. Information management behaviour of papaya growers of Karnataka: A comparative study. Indian Research Journal of Extension Education. 14(2): 31-35.

Chui, M., Manyika, J., Dobbs, R., Roxburgh, C., Sarrazin, H., Sands, G and Westergren, M. 2012. The social economy: Unlocking values and productivity through social technologies, Mckinsey global institute. http://www.mckinnsey.com/insights/hig htech_telecoms_internet/the_socialecon omy.

Eke, H.N., Charles, O.O and Odho, J.N. 2014. The use of social networking sites among the undergraduates students of university of Nigeria, Nukka, Library philosophy and practice (e-Journal). 
http://digitalcommons.unl.edu/ libphilprac/1195

ET tech. 2016. Indians internet growth rates is 4X global rate: Mary Meekers 2016 internet trends. http://tech.economictimes.indiantimes.c om /news/internet /india s internet uers-growth-rate-is-4x-of-global-ratemary-meeker/52550127.

Laxmipriya, U. 2017. Analysis of digital divide in agriculture information delivery. M.Sc. (Ag) Thesis. Indian Agricultural Research Institute, New Delhi, India.

Meera, N.S., Aruna, S.K., Praveen, R. and
Voleti, S.R. 2018. Digital disruption at field level: Tipping point experiments from rice sector. The Journal of Extension Education. 54 (4): 1-10.

We are social. 2017. Digital in 2017: Global overview. http://we aresocial.com/blog/ 2017/digital-in-2017-global-overview.

www.statista.com. 2020. Number of social media users worldwide from 2010 to 2021

(in billion). http://www.statista.com/statistics/27841 4/num ber-of-worldwide-socialnetwork-user/.

\section{How to cite this article:}

Sandeep, G. P., P. Prashanth, M. Sreenivasulu and Madhavilata, A. 2020. Social Media in Agriculture - A Profile Analysis. Int.J.Curr.Microbiol.App.Sci. 9(07): 2727-2736. doi: https://doi.org/10.20546/ijcmas.2020.907.322 